\title{
SILVER-RUTHENIUM DIOXIDE CONTACTS
}

\author{
D. J. PEDDER \\ The Plessey Company Limited, Allen Clark Research Centre, Caswell, Towcester, Northants, U.K.
}

(Received June 20, 1975)

\begin{abstract}
This paper describes the development of a novel electrical contact material, silver-ruthenium oxide, for use in light duty switching applications where low contact resistance values must be maintained. Material fabrication and contact resistance behaviour after exposure to a tarnishing atmosphere are described. An explanation for the low contact resistance values obtained for silver-ruthenium dioxide in comparison with pure silver is offered.
\end{abstract}

\section{INTRODUCTION}

Snap switches are used in a wide variety of contact applications. Some of these entail the switching of several amperes at relatively high voltages, others the switching of a few milliamperes at, typically, one volt. Some applications involve frequent operation, others very infrequent indeed. The contact material most commonly used in these devices is silver, due to its favourable physical properties and acceptable cost. The most arduous applications are those involving frequent rapid switching of current at a maximum rated level, and those involving very infrequent usage in devices operating at low voltages e.g. in $6 \mathrm{~V}$ d.c. alarm circuits. The former problems may be overcome by increasing the bulk of the contacts. Problems arising from the latter are, however, inherent to the contact material employed in the device. Tarnish films which build up on the contact surfaces (except on those of the more expensive noble metals such as gold and palladium), both during shelf life and during operation, eventually, after a period of weeks or years depending upon the environment, reach such a thickness that the circuit voltage is no longer sufficient to break them down, leading to device failure. Thus there exists a real need for a contact material that will perform as well as silver on load, but is superior to silver as far as shelf life is concerned, and which is still relatively inexpensive.

A comparative study of the tarnishing and contact resistance behaviour of silver and internally oxidised silver-cadmium oxide in hydrogen sulphide bearing atmospheres had shown that a second phase present in the silver surface could have a significant effect upon tarnishing and contact resistance ${ }^{1}$. It was therefore felt that advantage could be taken of this effect to produce an improved silver base material for light duty applications. It was initially hoped to produce a silver base material containing a selected oxide phase situated in the free surface using a process of controlled external oxidation in which the chosen alloying element would diffuse to the surface to be converted to the oxide ${ }^{2}$. Ruthenium was chosen as a suitable element since its stable oxide, $\mathrm{RuO}_{2}$ is highly electrically conducting. For economic reasons the ruthenium content was limited to a maximum of about 3 per cent by weight (a silver-1 wt.\% ruthenium material would cost approximately one third more than pure silver). A search of the rather small amount of data in the literature ${ }^{3,4}$ and early experimental work in this laboratory indicated, however, that ruthenium is virtually insoluble in silver even at temperatures above the melting point of silver. This work also indicated that the phase diagram by Elliot ${ }^{3}$ is probably incorrect. Thus it would not be possible to produce a silver-ruthenium oxide material by controlled external or internal oxidation of a simple solid solution as is done, for example, in the preparation of silver-cadmium oxide by internal oxidation. It was considered of interest, however, to make silver-ruthenium oxide by a powder metallurgical method and study the effects of discrete particles of the conducting oxide situated in the free surface of the silver upon the tarnishing behaviour and contact resistance.

\section{MATERIAL PREPARATION}

The experimental samples were prepared from 99.99\% purity silver powder supplied by the Sheffield Smelting Company and S grade ruthenium powder supplied by International Nickel Limited. The silver powder had a mean particle size of 17 microns diameter and the ruthenium powder a mean particle 
size of 2 microns diameter, measured as the mean linear intercept on a polished section of the powders suspended in mounting resin.

The powders were mixed in the desired proportion by tumbling in a horizontally revolving drum. Test samples were then compacted at 10 t.s.i., sintered and oxidised either simultaneously or sequentially. The samples were finally coined to increase the density to a value approaching the theoretical value. The surfaces contained ruthenium oxide particles both in and proud of the silver surface.

An optical micrograph of a polished and etched section of a silver-ruthenium oxide material is shown in Figure 1. The dark ruthenium oxide particles are

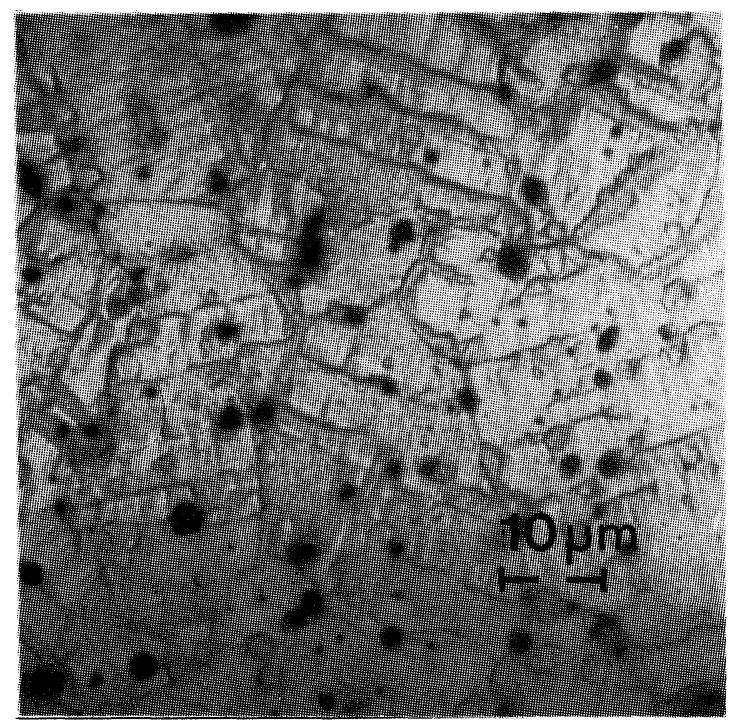

FIGURE 1 Optical micrograph of a polished and etched section of a silver-ruthenium oxide material, $\times 1000$.

well dispersed and typically 3 microns in diameter. A scanning electron micrograph of the surface of a silver-ruthenium oxide sample is shown in Figure 2. The oxide phase is shown to be sitting proud of the surface of the silver matrix.

\section{CONTACT RESISTANCE TESTING}

Silver-ruthenium oxide samples together with pure silver control samples prepared by a similar route from the same silver powder and silver-cadmium oxide samples obtained commercially were exposed to static, moist hydrogen sulphide atmospheres ( $700 \mathrm{~mm} \mathrm{H}_{2} \mathrm{~S}, 19 \mathrm{~mm} \mathrm{H}_{2} \mathrm{O}$ ) for up to 48 hours

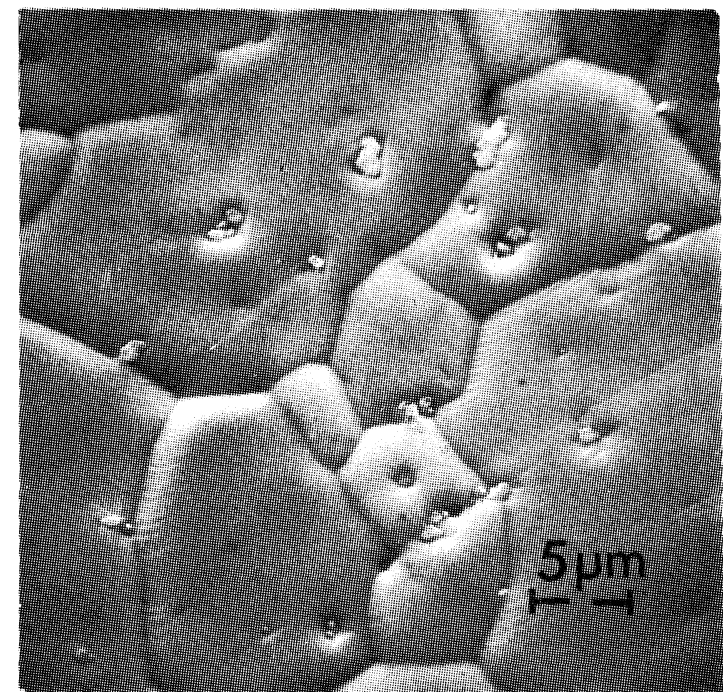

FIGURE 2 A scanning electron micrograph of the surface of a silver-ruthenium oxide material, $\times 2000$.

at ambient temperature. Visual examination of the contacts after exposure revealed that the silverruthenium oxide samples had blackened just as severely as the pure silver samples.

Contact resistance values were then determined between the samples and a polished spectrographically pure silver reference surface as a function of contact force. The silver ruthenium oxide samples were found to give low contact resistance values even at small contact forces, in contrast to the pure silver and silver-cadmium oxide samples. A typical set of contact resistance values as a function of contact force are plotted in Figure 3.

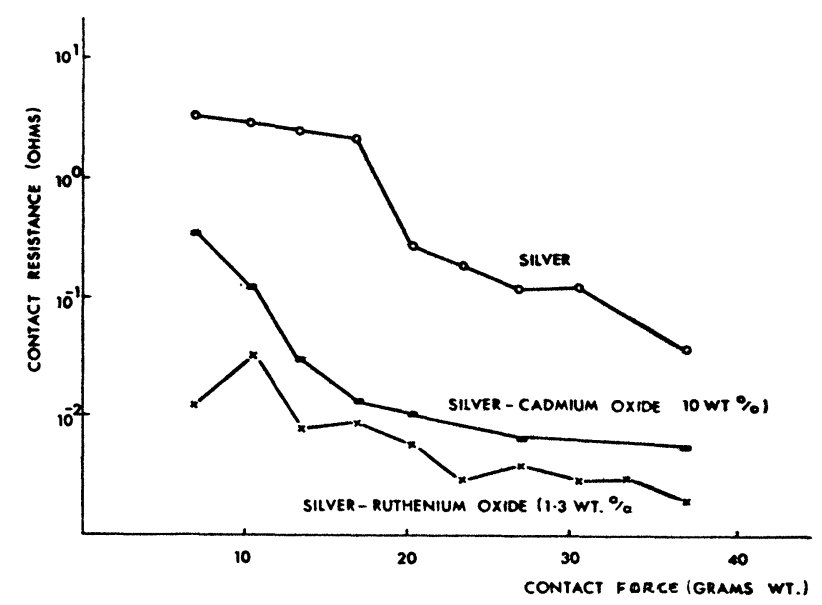

FIGURE 3 Contact resistance plotted as a function of contact force for silver, silver-cadmium oxide and silverruthenium oxide after 21 hours exposure to a moist hydrogen sulphide atmosphere. 


\section{DISCUSSION AND CONCLUSIONS}

The ability to maintain low contact resistance, despite an apparently severely tarnished surface, is, at first sight, somewhat surprising. It has been shown however by scanning electron microscopy that the as-prepared silver-ruthenium oxide surfaces contain ruthenium oxide particles sitting proud of the surface. It is therefore possible that, upon tarnishing, small islands of a non-tarnishing conducting phase provide conducting paths through an otherwise tarnished surface. The oxide particles, being harder than the tarnish films formed on the silver surfaces, may also rupture such films on the opposing contact. The ruthenium oxide particles appear proud of the silver surface as a result of expansion of the ruthenium metal particles in the surface upon oxidation. This is due to the considerable difference in molar volumes of ruthenium oxide $(19.1 \mathrm{cc})$ and ruthenium metal $(8.2 \mathrm{cc})$.

Although the tarnishing environment is many times more severe than encountered in practice, and therefore the relation of the results presented to practical tarnishing behaviour is open to some question ${ }^{5}$ the results of the accelerated tarnishing experiments indicate that silver-ruthenium dioxide may be a useful material for applications where low contact resistance values are desired. There exist a number of other oxides ${ }^{6}$, which might usefully be studied as potentially beneficial additions to silver to improve its contact resistance behaviour and it is hoped that further work in this area will confirm the present findings and reveal a useful solution to one of the problems associated with light duty electrical contacts.

\section{REFERENCES}

1. The Plessey Company, Internal Research Report.

2. J. L. Meijering, Internal Oxidation in Alloys, Advances in Materials Research, 5, 64 (1971).

3. R. P. Elliot, Constitution of Binary Alloys, First Supplement, McGraw-Hill, p. 19 (1965).

4. A. A. Rudnitskii and O. A. Novikova, Zh. Neorgan. Khim. 4, 1596-1600 (1959). Russ. J. Inorg. Chem. 4, 719-722 (1959).

5. W. A. Crossland, E. Knight and C. R. Wright, The Accelerated Tarnish Testing of Contacts and Connectors Employing Silver Alloy Contacts, Proc. Holm Seminar on Electrical Contact Phenomena, pp. 265-282 (1973).

6. C.N.R. Rao and G. V. Subba Rao, "Electrical conduction in metal oxides", Phys. Stat. Sol.(a) 1, 597 (1970). 

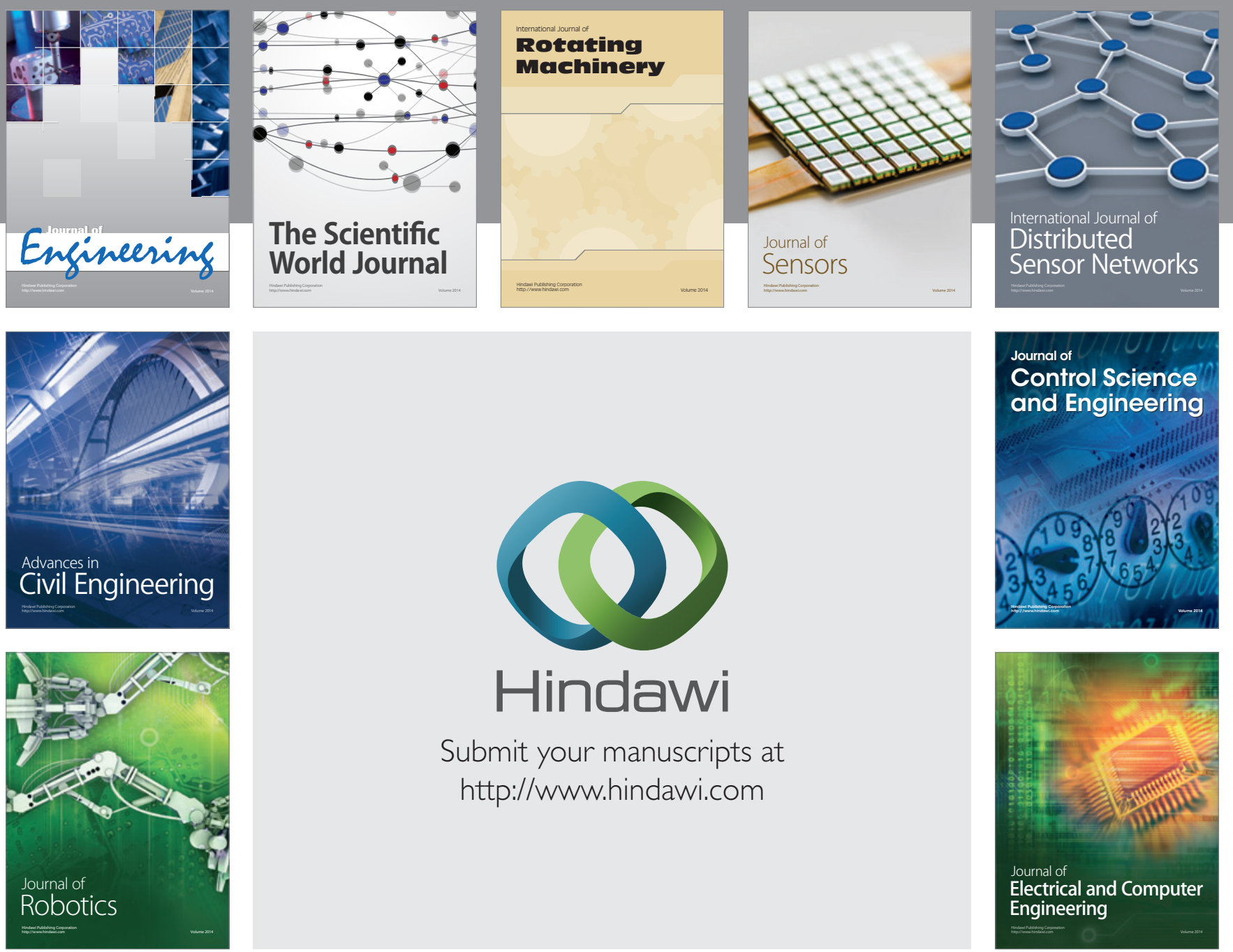

Submit your manuscripts at

http://www.hindawi.com
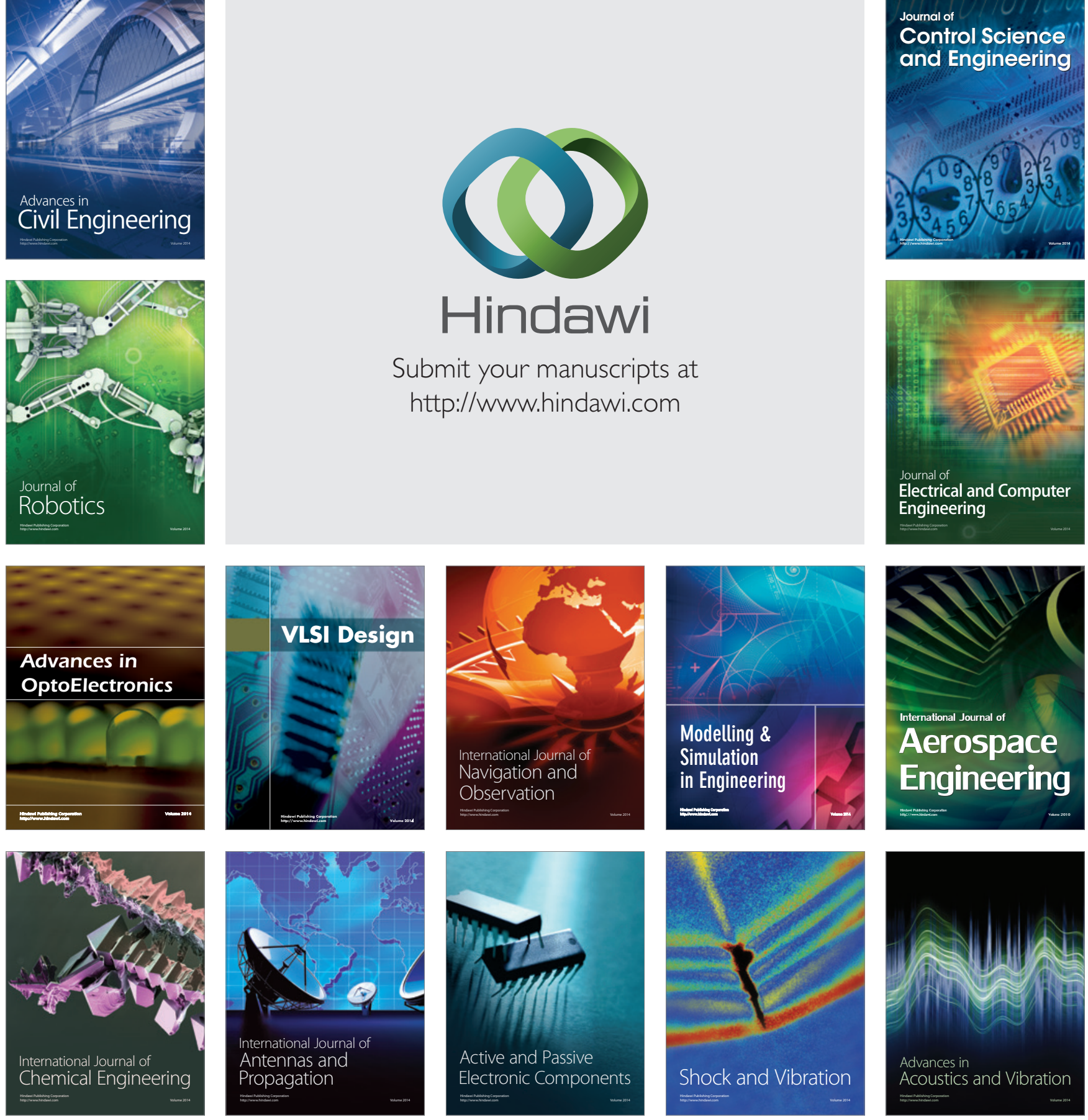